\title{
Fear, Anxiety and Practice Modifications among Dentists to Fight against Novel Coronavirus Disease (COVID-19) Outbreak in India: A Questionnaire Based Study
}

\author{
Sharath Kumar Shetty ${ }^{1}$, Vijayananda K Madhur ${ }^{2}$, Eva Emelya Jose ${ }^{3 *}$, Mahesh Kumar Y ${ }^{4}$
}

\begin{abstract}
${ }^{1}$ Professor \& HOD, Department of Orthodontics and Dentofacial Orthopaedics, K. V. G. Dental College and Hospital, Sullia, Karnataka, India
${ }^{2}$ Reader, Department of Orthodontics and Dentofacial Orthopaedics, K. V. G. Dental College and Hospital, Sullia, Karnataka, India

${ }^{3}$ Post Graduate Student, Department of Orthodontics and Dentofacial Orthopaedics, K. V. G. Dental College and Hospital, Sullia, Karnataka, India

${ }^{4}$ Professor, Department of Orthodontics and Dentofacial Orthopaedics, K. V. G. Dental College and Hospital, Sullia, Karnataka, India
\end{abstract}

DOI: $10.36347 /$ sjds.2020.v07i12.009

| Received: 12.12.2020 | Accepted: 24.12.2020 | Published: 30.12.2020

*Corresponding author: Eva Emelya Jose

\section{Abstract}

Original Research Article

Since its emergence in December 2019, corona virus disease 2019 (COVID-19) has impacted several countries, and making it a global public threat. The routes of transmission are direct contact, and droplet and possible aerosol transmissions. Due to the unique nature of dentistry, most dental procedures generate significant amounts of droplets and aerosols, posing potential risks of infection transmission. The current study was conducted to assess anxiety and fear of getting infected among dentists while working during the current novel coronavirus diseases (COVID-19) outbreak and dentist's knowledge about various practice modifications to combat COVID-19 has been evaluated. The questionnaire study was conducted using an online survey from July 2020 to December 2020.

Keywords: COVID-19, Coronavirus, Dental Practice, Fear.

Copyright $\odot$ (C)20 The Author(s): This is an open-access article distributed under the terms of the Creative Commons Attribution 4.0 International License (CC BY-NC 4.0) which permits unrestricted use, distribution, and reproduction in any medium for non-commercial use provided the original author and source are credited.

\section{INTRODUCTION}

The novel COVID-19 came under limelight back (December 2019) and has been declared a pandemic by WHO [1]. By the end of 2019, a pneumonia outbreak with unknown etiology occurred in Wuhan, China. Most of the cases were linked to a local seafood market selling live animals, suggesting that the pathogens were transmitted from animals to humans, soon escalating to human-to-human transmission. The pathogen was identified and named as 2019 novel coronavirus (2019-nCoV), and the disease was named corona virus disease 2019 (COVID-19), which stands for coronavirus disease 2019 [2].

The COVID-19 is believed to be transferred from animals to humans [3]. The other two similar viruses discovered earlier were severe acute respiratory syndrome coronavirus (SARS-COV) and Middle east respiratory syndrome [4]. The COVID-19 has also been called SARS-CoV-2 but the former name has gained more popularity than the latter name [5]. The COVID19 causes human illnesses which could range from a common cold to more severe respiratory problems like pneumonia [6]. Unfortunately, there is no vaccine available for COVID-19 and the only form of treatment available is to provide symptomatic treatment to the patients with oxygen supplementation [7].

Dentistry is a profession where the dentist works in close proximity to the patient's mouth and many procedures produce aerosol which is a mixture of water (from a dental instrument like high speed hand piece) and patient's saliva or blood [8]. These aerosols could result in the spread of infection and diseases including COVID-19 [9]. In an article published by the New York Times has identified dentists who are at the highest risk of getting COVID-19 from their patients due to cross infection [10].

\section{MATERIALS AND METHODS}

The present study was a cross- sectional questionnaire-based survey conducted among the dentists in India between July 2020 and December 2020. A 21 questionnaire were included in the study to evaluate the Fear, Anxiety and Practice Modifications Among Dentists To Fight Against COVID-19 Outbreak In India. The questionnaire was in English language and open ended and self-administered. The Ethical approval was obtained from the Ethics committee KVG dental college Sullia, Dakshina Kannada. Soft copy of questionnaire was delivered through mail, whatsapp and 
Sharath Kumar Shetty et al., Sch J Dent Sci, Dec, 2020; 7(12): 350-357

whatsapp groups to maximum possible number of orthodontists in India including PG residents. A total of 207 responses were included in the study.

\section{Questionnaire}

1. Are You Afraid of Getting Infected with COVID19 from a Patient and Co-Worker?
Yes ( )
No ( )
Unaware ( )

2. Are You Anxious When Providing Treatment to a Patient who is Coughing or Suspected of being Infected with COVID-19?
Yes ( )
No ( )
Unaware ( )

3. Do You want to Close Your Dental Practice until the Number of COVID-19 Cases Starts Declining? Yes ( ) No ( ) Unaware ( )

4. Do You Feel Nervous when Talking to Patients in Close Vicinity?

Yes ( ) No ( ) Unaware ( )

5. Do You have Fear that You Could Carry the Infection from Your Dental Practice back to Your Family?
Yes ( )
No ( )
Unaware ( )

6. Are You Afraid of Getting Quarantined if get Infected?
Yes ( )
No ( )
Unaware ( )

7. Are You Anxious about the Cost of Treatment if You Get Infected?
Yes (
No (
Unaware (

8. Are You Aware of the Mode of Transmission of COVID-19?

Yes ( ) No ( ) Unaware ( )

9. Are You Updated with the Current WHO Guidelines for Cross-Infection Control regarding COVID-19?

Yes ( ) No ( ) Unaware ( )

10. Are You currently Asking every Patient's Travel History before Performing Dental Treatment? Yes () No ( ) Unaware ( )

11. Are You currently Taking every Patient's Body Temperature before Performing Dental Treatment? Yes () No ( ) Unaware ( )

12. Are You Delaying Dental Treatment of Patients Showing Suspicious Symptoms?

Yes ( ) No ( ) Unaware ( )

13. Do You Think Surgical Mask is enough to Prevent Cross-Infection of COVID 19?

Yes ( ) No ( ) Unaware ( )
14. Do You Think N-90 Mask should be Routinely Worn in Dental Practice due to the Current Outbreak?

Yes ( ) No ( ) Unaware ( )

15. Have You Ever Worn an N-90 Mask while Treating a Patient in Your Dental Practice?

Yes () No ( ) Unaware ( )

16. Do You Routinely Follow Universal Precautions of Infection Control for Every Patient?

Yes ( ) No ( ) Unaware ( )

17. Do You Use Rubber Dam Isolation for Every Patient?

Yes ( ) No ( ) Unaware ( )

18. Do You Use High-Volume Suction in Your Practice for Every Patient?

Yes ( ) No ( ) Unaware ( )

19. Do You Ask Every Patient to Rinse His/Her Mouth with Anti-Bacterial Mouthwash before Treatment? Yes ( ) No ( ) Unaware ( )

20. Do You Wash Hands with Soap andWater/Use Sanitizer Before and After Treatment of Every Patient?

Yes ( ) No ( ) Unaware ( )

21. Are You Aware of which Authority to Contact if You Come Across a Patient with Suspected COVID 19 Infection?

Yes ( ) No ( ) Unaware ( )

\section{RESULTS}

The responses of a total of 207 dentists were included in the study. The results of the study are presented with the help of pie charts below.

\section{N- Number of Response}

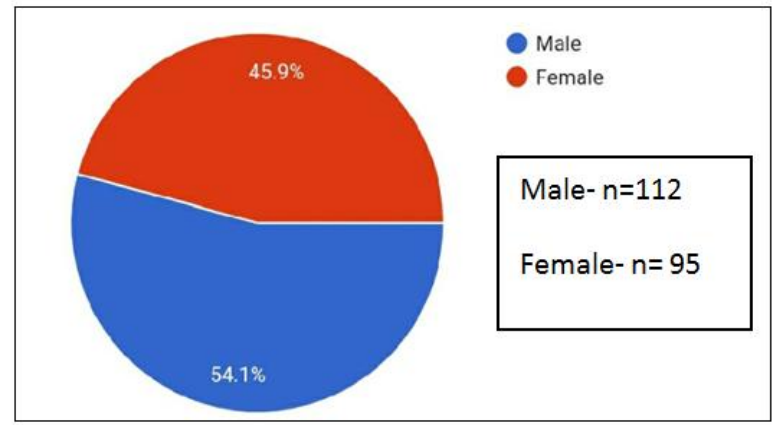

Fig-1: Gender Based Distribution 


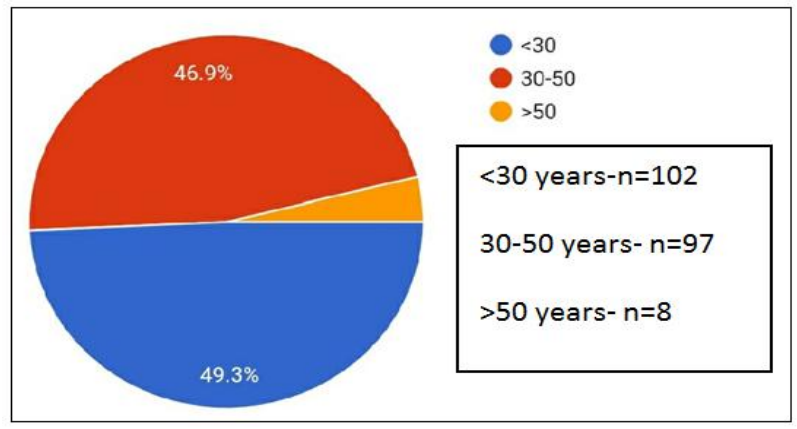

Fig-2: Age Based Distribution

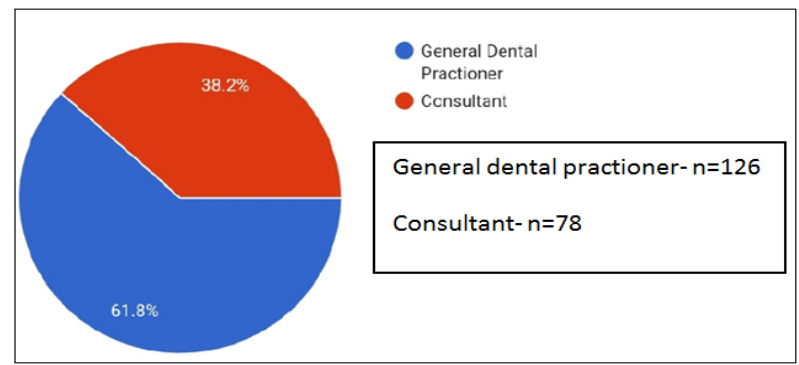

Fig-3: Designation

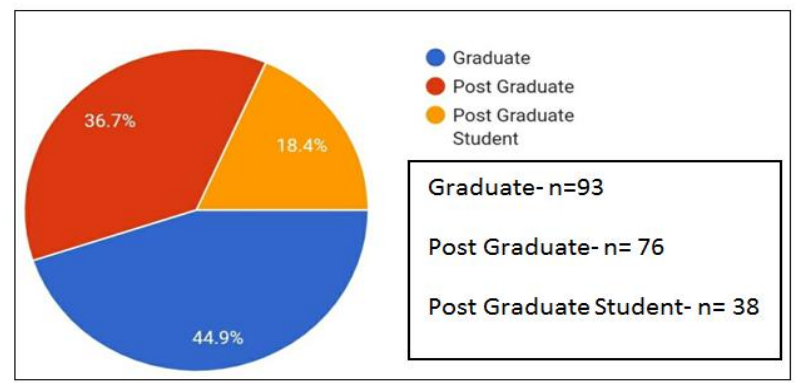

Fig-4: Qualification

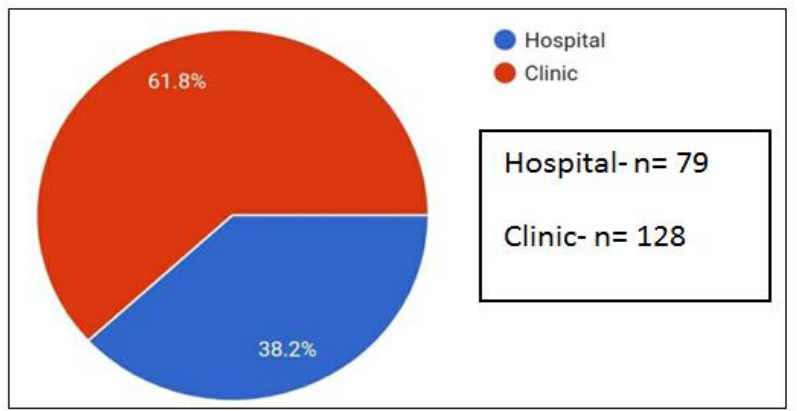

Fig-5: Workplace

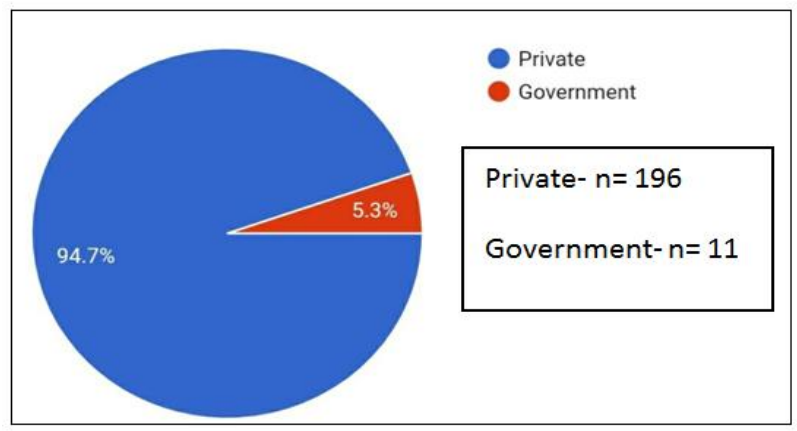

Fig-6: Work setting

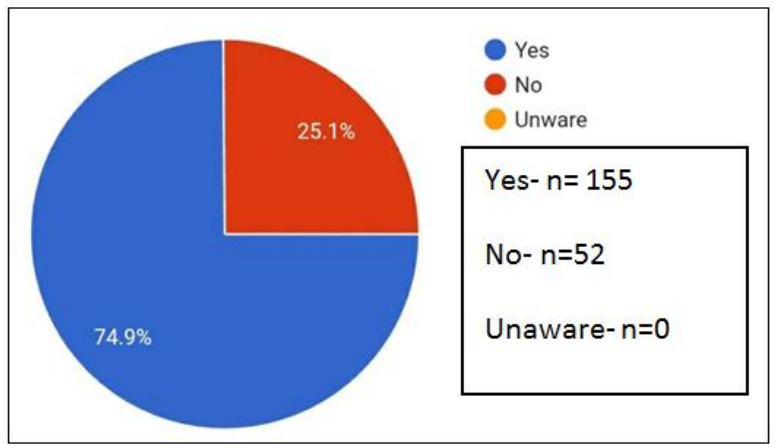

Fig-7: Afraid of getting infected with covid-19 from patient and co-worker

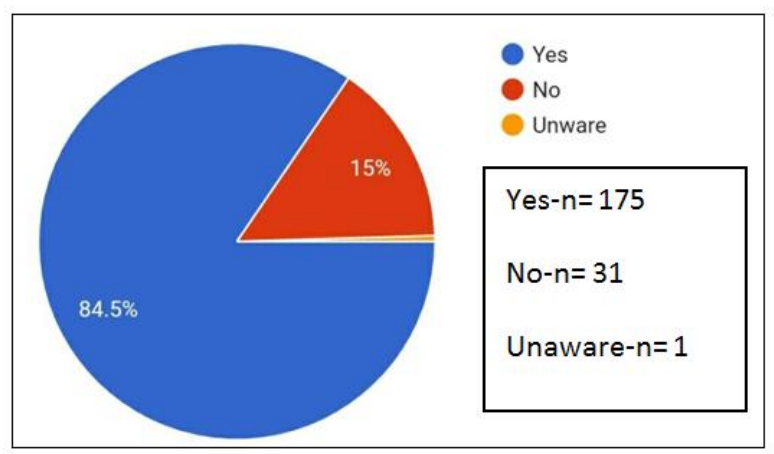

Fig-8: Anxious when providing treatment to a patient who is coughing or suspected of being infected with covid-19

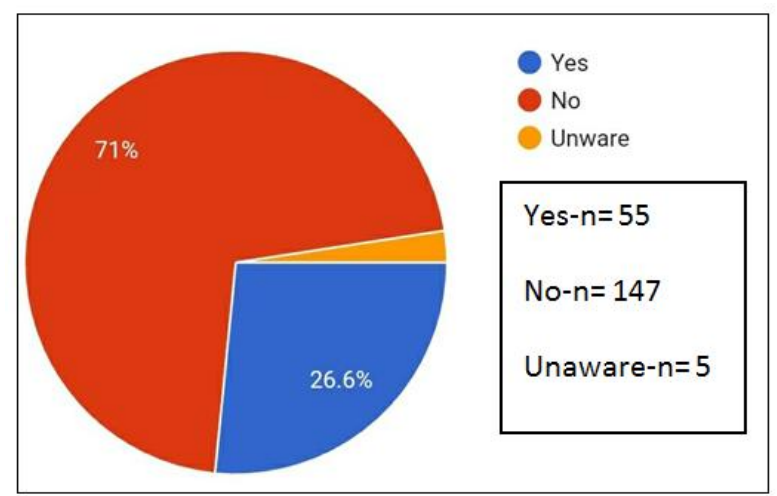

Fig-9: Want To Close Your Dental Practice Until the Number of COVID-19 Cases Starts Declining

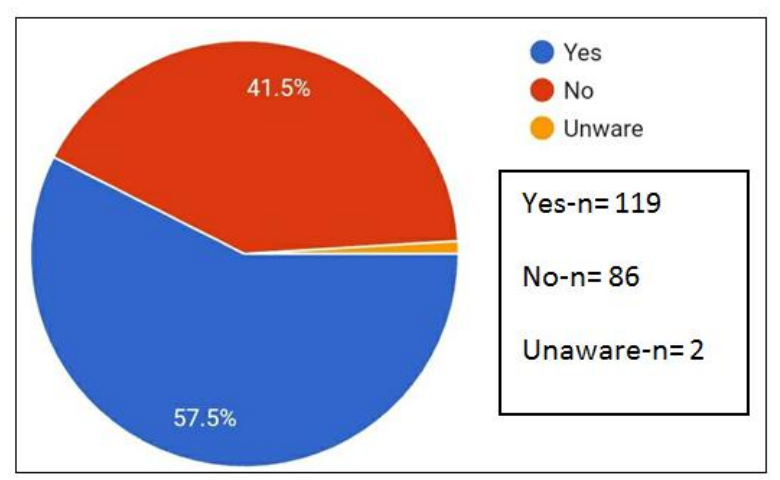

Fig-10: Feel Nervous when Talking to Patients in Close Vicinity 


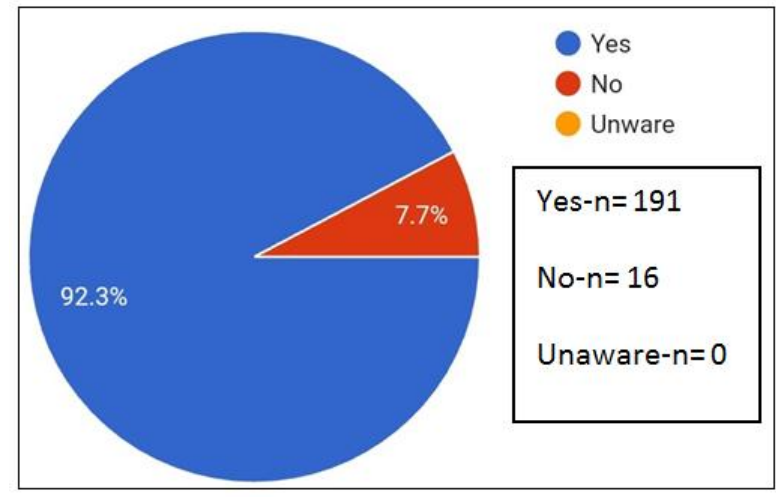

Fig-11: Fear that You Could Carry the Infection from Your Dental Practice back to Your Family

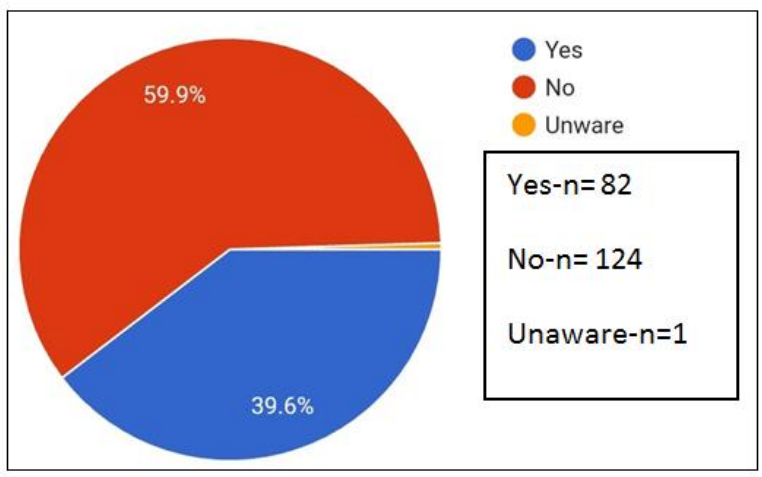

Fig-12: Afraid Of Getting Quarantined If Get Infected

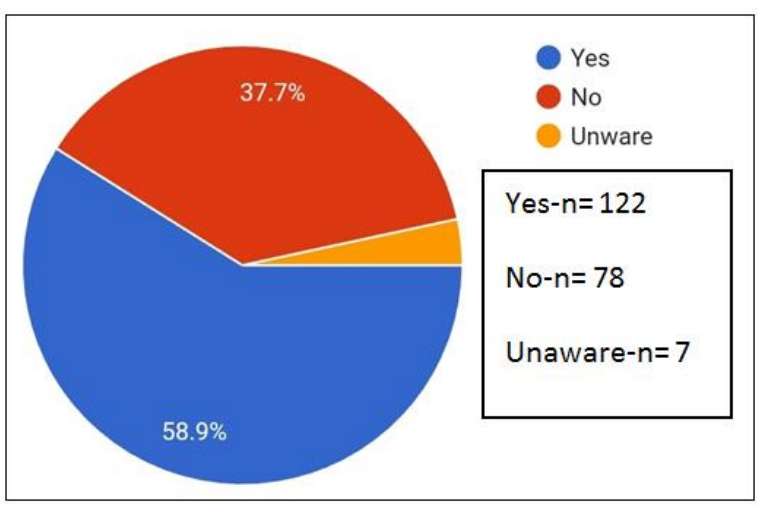

Fig-13: Anxious about the Cost of Treatment if You Get Infected

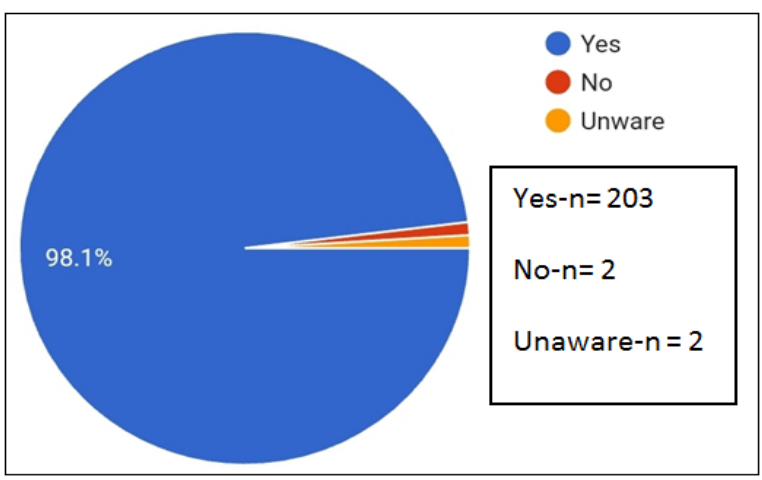

Fig-14: Aware of the Mode of Transmission of COVID-19

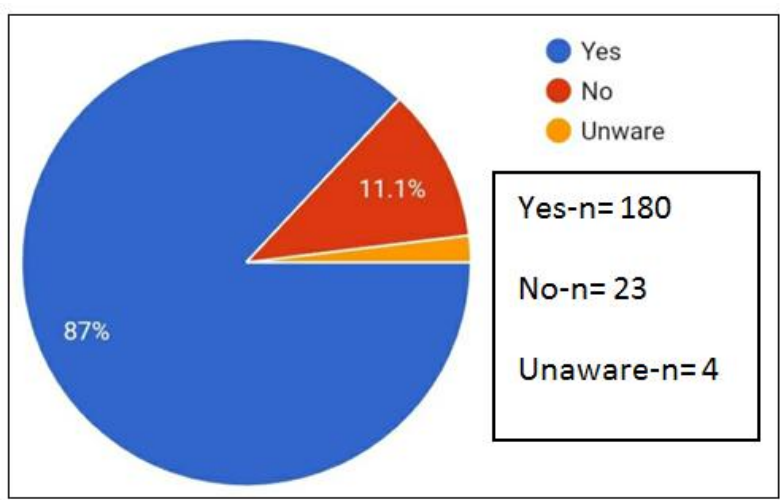

Fig-15: Updated with the WHO Guidelines for Cross-Infection Control regarding COVID-19

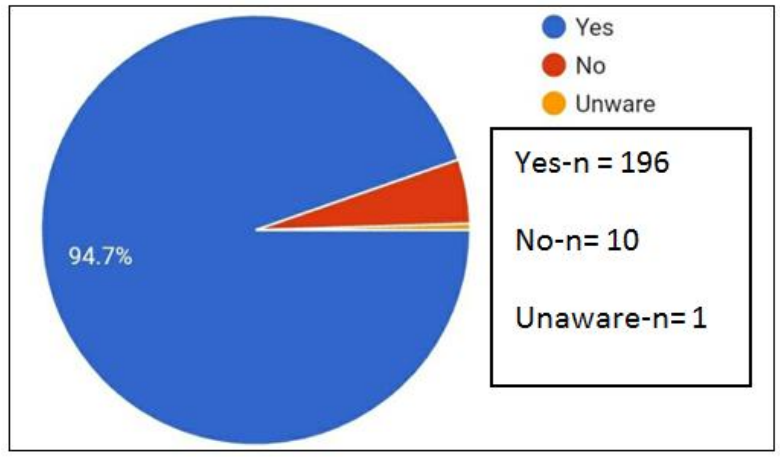

Fig-16: Currently Asking Every Patient's Travel History before Performing Dental Treatment

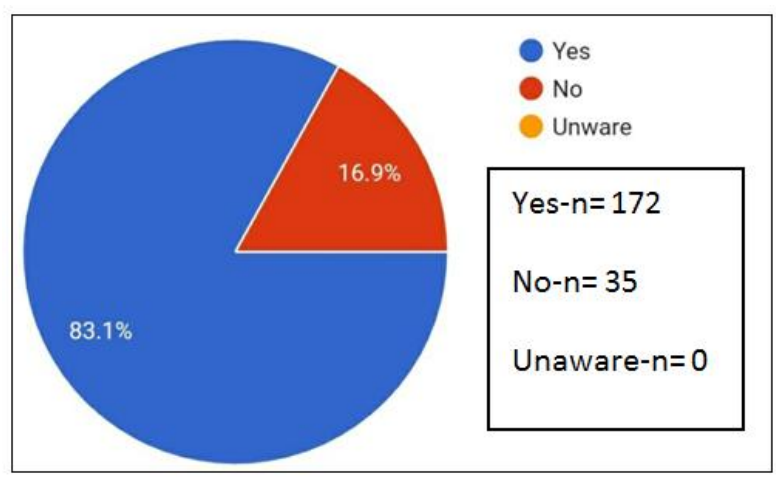

Fig-17: Currently Taking Every Patient's Body Temperature before Performing Dental Treatment

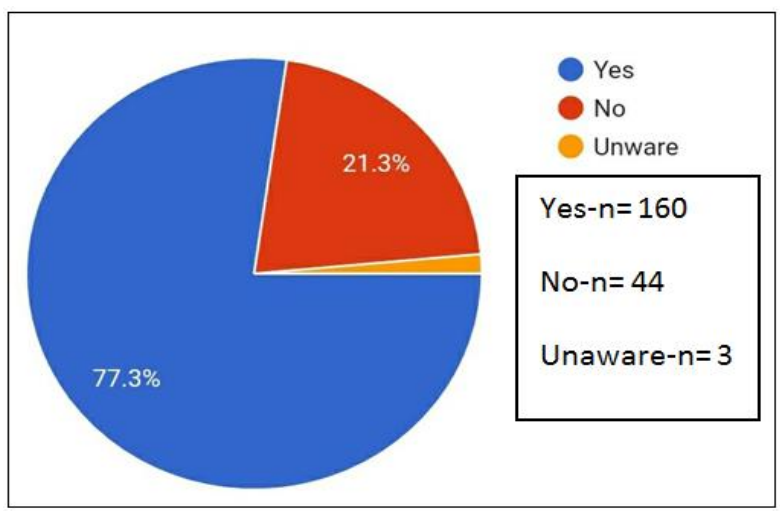

Fig-18: Delaying Dental Treatment of Patients Showing Suspicious Symptoms 


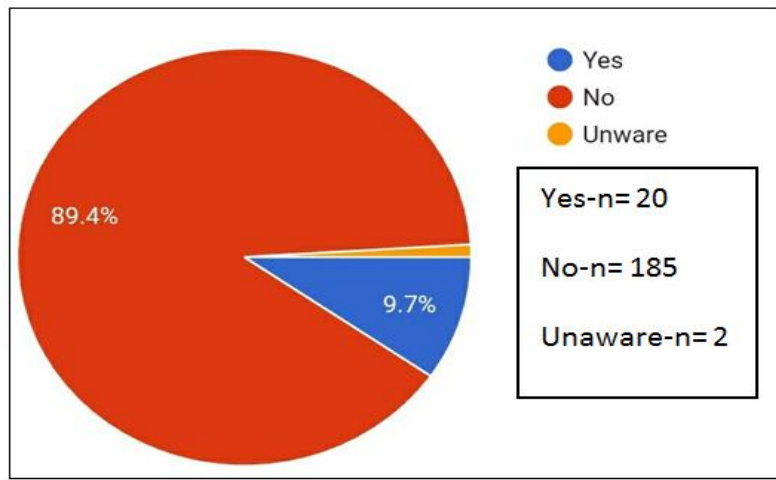

Fig-19: Surgical Mask Is Enough to Prevent CrossInfection of COVID 19

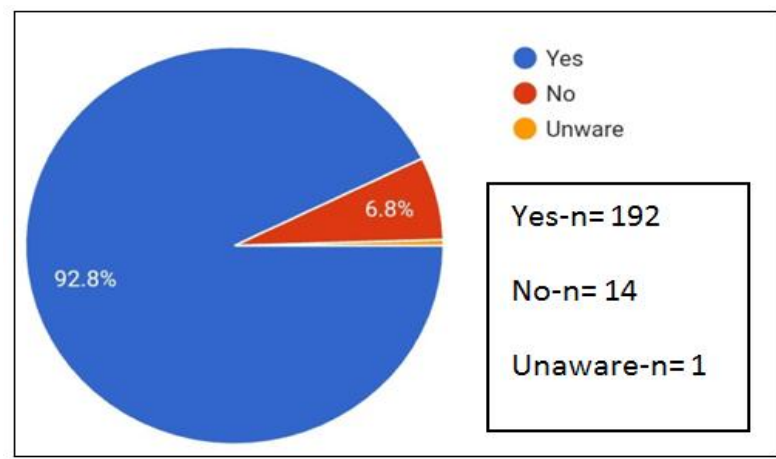

Fig-20: N-90 Mask should be Routinely Worn in Dental Practice due to the Current Outbreak

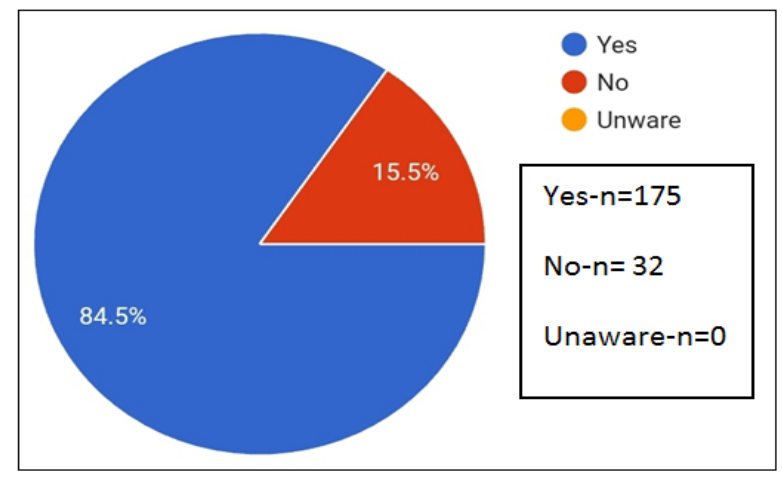

Fig-21: Ever Worn An N-90 Mask While Treating A Patient In Your Dental Practice

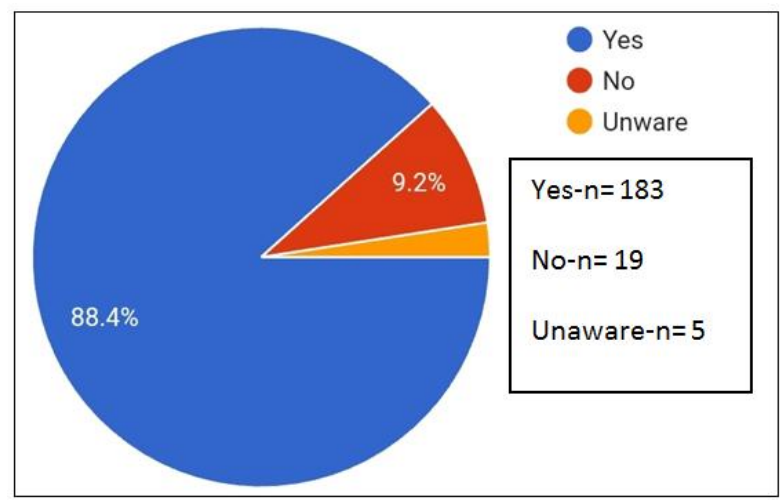

Fig-22: Routinely Follow Universal Precautions of Infection Control for Every Patient

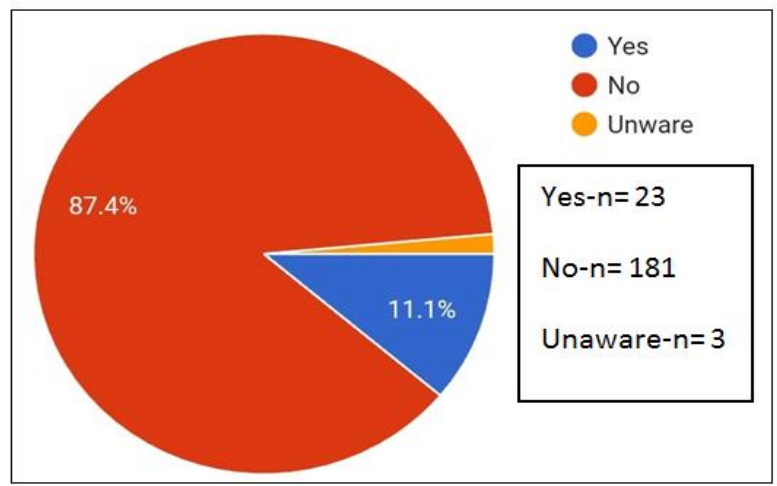

Fig-23: Use Rubber Dam Isolation for Every Patient

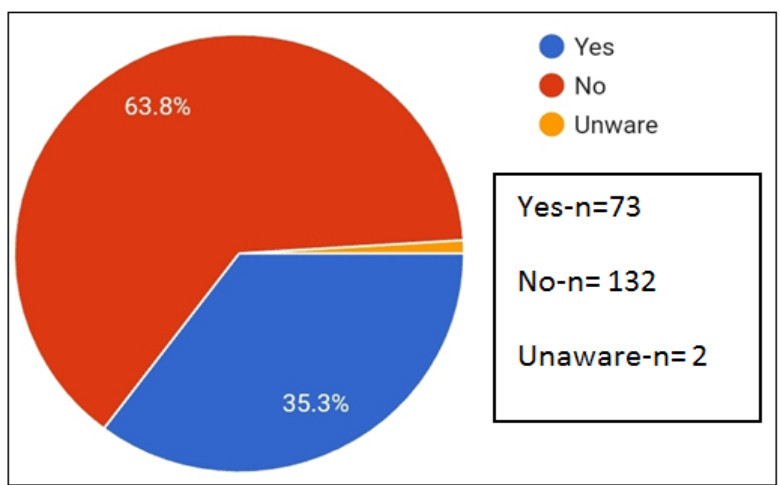

Fig-24: Use High-Volume Suction in Your Practice for Every Patient

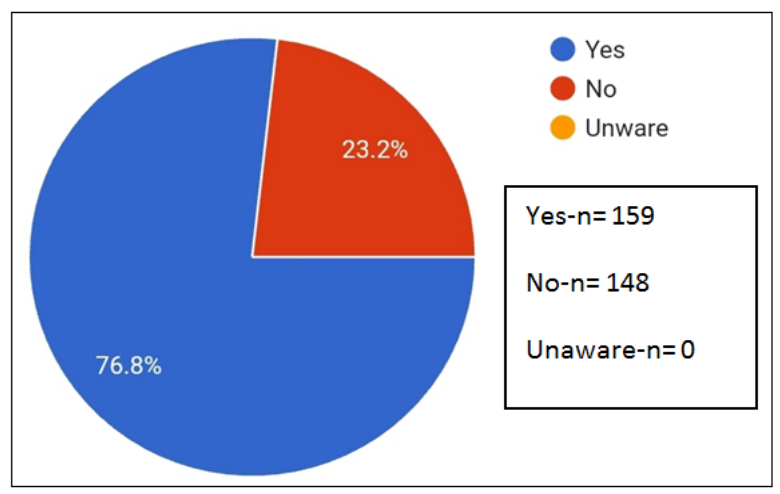

Fig-25: Ask Every Patient to Rinse His/ Her Mouth with Anti-Bacterial Mouthwash before Treatment

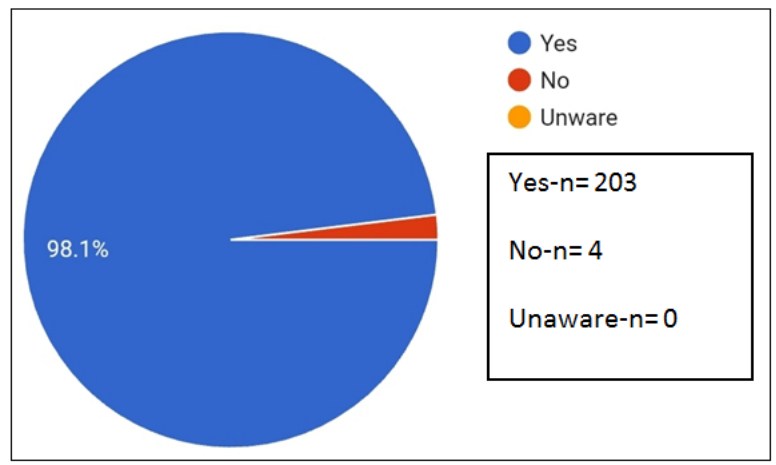

Fig-26: Wash Hands with Soap and Water/ Use Sanitizer before and After Treatment of Every Patient 
Sharath Kumar Shetty et al., Sch J Dent Sci, Dec, 2020; 7(12): 350-357

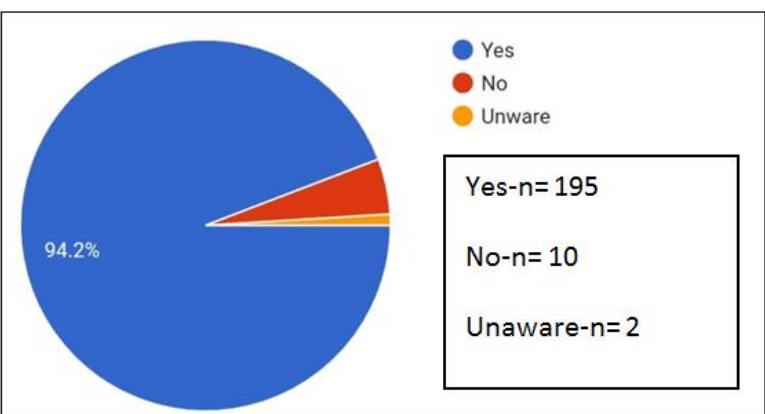

Fig-27: Aware Of Which Authority to Contact, If You Come Across A Patient With Suspected COVID 19 Infection

A total number of 207 participants from India submitted the completed questionnaire with a total of 21 questions. Out of a total of 207 participants were 112 $(45.9 \%)$, male and 95(45.9\%), female. Age groups < 30 years, $97(46.9 \%)$; 30- 50 years, $97(46.9 \%)$ and $>50$ years, 8 (3.9\%). By designation, $126(61.8 \%)$ were general dentists, $78(38.2 \%)$ consultant. By qualification 93(44.9\%) were graduates, $76(36.7 \%)$ postgraduates, $38(18.4 \%)$ postgraduate students. The majority of participants $128(61.8 \%)$ were working in a clinic while $79(38.2 \%)$ were working in hospital. Dentists were mostly from a private setup, 196(94.7\%) and 11(5.3\%) from a government employee.

$74.9 \%$ of participants were afraid of getting infected with COVID-19 from either a patient or a coworker. $84.5 \%$ were anxious, while treating a coughing or a patient suspected to be infected with COVID-19. $71 \%$ of dentists did not want to close their dental practices until the number of COVID-19 cases start to decline. $57.5 \%$ of participants felt nervous when talking to patients in close vicinity, $92.3 \%$ were afraid of carrying the infection from dental practice to their families, and $59.9 \%$ were afraid of getting quarantined if they got infected. $58.9 \%$ were concerned about the cost of treatment, if they got infected. $98.1 \%$ were aware of its mode of transmission of the disease, and $87 \%$ were updated with the WHO guidelines for crossinfection control. $94.7 \%$ were asking about the patient's travel history. Every patient's body temperature before performing dental treatments recorded by $83.1 \%$, and $77.3 \%$ delayed dental treatment of patients who showed suspicious symptoms. $89.4 \%$ accepted that a surgical mask is not enough to prevent cross-infection of COVID-19. $92.8 \%$ favored the use of N-95 masks for routine dental procedures during the current outbreak. $84.5 \%$ were wearing an N-95 mask while treating a patient. Although the majority $(88.4 \%)$ recommended routine universal precautions of infection control, $87.4 \%$ did not use rubber dam isolation for every patient. $63.8 \%$ did not use high-volume suction for every patient. Meanwhile, $76.8 \%$ did ask their patients to rinse the mouth with antibacterial mouthwash before dental treatment. $98.1 \%$ of dentists washed their hands with soap and water or sanitizer before and after treatment of patients. $94.2 \%$ were aware of the proper authority to contact if they came across a patient with a suspected COVID-19 infection.

\section{DISCUSSION}

Aerosol transmission is also a possible route of transmission when there is an exposure to high concentrations of aerosols in a relatively closed environment. Routine dental procedures generate aerosols, which pose potential risks to the dental care personnel and patients [11]. In the present study $92.3 \%$ of the dentist were afraid of carrying the infection from dental practice to their families, studies on previous outbreaks of similar infectious diseases, healthcare workers showed the fear of getting infected while treating an infected patient, or infecting a family member $[12,13]$. . Patient screening: As is the routine, dentists should take a thorough medical history from each patient and confirm the health status at each recall visit. During this outbreak, targeted screening questions for COVID-19 must be asked. These questions should include personal, travel, and epidemiological history. Temperature and lower respiratory tract symptoms should be closely monitored [11].

In the present study the majority of the participants were aware of the COVID-19 mode of spread and transmission and the guidelines issued by the WHO for cross-infection control in the dental practice including asking patient's travel history and recording patient's body temperature [14]. During dental procedures that generate aerosols, rubber dam provides barrier protection from the primary source and will virtually eliminate all pathogens emerging from respiratory secretion.

In the present study majority of the dentist $(87.4 \%)$ did not use rubber dam, only $11.1 \%$ of the participant used it in their practice. If the rubber dam is placed correctly, the only source of contamination would be the tooth that is undergoing treatment [15]. Application of rubber dam during cavity preparation showed a significant reduction in the spread of microorganisms by $90 \%$ [16]. Rubber dam is applied in all aerosol-generating procedures. The use of highvolume suction is also considered an essential means to control aerosols evacuation during dental procedures and should be used for the majority of patients [11], but in the present study $63.8 \%$ didn't use and $35.3 \%$ used high -volume suction. Meanwhile in comparison with the use of rubber dam the use of high-volume suction is more.

Preprocedural mouth rinse is one of the most effective methods of reducing the proportion of microorganisms in oral aerosols [17, 18]. A meta analysis showed that the use of pre procedural mouth rinse, including chlorhexidine ( $\mathrm{CHX}$ ), essential oils, and cetylpyridinium chloride (CPC), resulted in a mean reduction of $68.4 \%$ colony-forming units in dental 
aerosol [19]. Although the effect of preprocedural mouth rinse against corona virus is still unknown, it has been proven that $\mathrm{CHX}$ is effective against several infectious viruses, including herpes simplex virus (HSV), human immunodeficiency virus (HIV), and hepatitis B virus (HBV) [20]. About $0.12 \%$ CHX was used as a pre procedural mouth rinse. For patients who develop mucosal irritation or other side effects such as tongue stain, $0.05 \% \mathrm{CPC}$ could be a good alternative [18].

There is a growing awareness of the importance of hand washing in the prevention of acute respiratory infections. During the outburst of SARS, several epidemiological studies suggested that hand washing with soap and 70\%-90\% alcohol-based hand rubs (ABHRs) was effective in curbing SARS transmission [21, 22]. The WHO (2020c) stated that hand hygiene includes either cleansing hands with an ABHR or with soap and water; both methods are equally effective [23]. ABHRs are preferred if the hands are not visibly soiled; if the hands are visibly soiled, water and soap should be used. As suggested by WHO, hand hygiene should be performed before touching a patient, before any cleaning or aseptic procedure is performed, after exposure to body fluid, after touching a patient, and after touching a patient's surroundings [24]. At minimum, a medical mask (surgical or procedure mask) was used if working at a distance of less than $1 \mathrm{~m}$ from the patient. When performing aerosol generating procedures (using highspeed handpiece, air-water syringe, and ultrasonic scaler), a particulate respirator that is at least as protective as a National Institute for Occupational Safety and Health (NIOSH)-certified N95, or equivalent, was used. When performing emergency dental treatment with suspected COVID-19 cases, a higher level of respiratory protection should be considered [11].

\section{CONCLUSION}

Overall, this study sheds light on the association of COVID-19 disease and practice modification in the field of dentistry. Dentists, by nature, are at high risk of exposure to infectious diseases. The emergence of COVID-19 has brought new challenges and responsibilities to dental professionals. A better understanding of about transmission and its implication in dentistry can help us identify and rectify negligence in daily dental practice. In addition to the standard precautions, implementation of special precautions could prevent disease transmission from asymptomatic carriers. These special precautions would not only help control the spread of COVID-19 but also serve as a guide for managing other respiratory diseases.

\section{REFERENCES}

1. Cucinotta D, Vanelli M. Who Declares COVID-19 a pandemic. Acta Biomed. 2020; 91:157-60.
2. Ge ZY, Yang LM, Xia JJ, Fu XH, Zhang YZ. Possible aerosol transmission of COVID-19 and special precautions in dentistry. Journal of Zhejiang University-SCIENCE B. 2020 Mar 16:18.

3. Gorbalenya AE, Baker SC, Baric RS, de Groot RJ, Drosten C, Gulyaeva AA, Haagmans BL, Lauber C, Leontovich AM, Neuman BW, Penzar D. The species severe acute respiratory syndrome related coronavirus: classifying 2019-nCoV and naming it SARS-CoV-2. Nat Microbiol 5: 536-544.

4. Wax RS, Christian MD. Practical recommendations for critical care and anesthesiology teams caring for novel coronavirus (2019-nCoV) patients. Can J Anesth/J Can Anesth. In Press. 2020; 350.

5. Wu Y, Ho W, Huang Y, Jin DY, Li S, Liu SL, Liu X, Qiu J, Sang Y, Wang Q, Yuen KY. SARS$\mathrm{CoV}-2$ is an appropriate name for the new coronavirus. The Lancet. 2020 Mar 21;395(10228):949-50.

6. Cascella M, Rajnik M, Cuomo A, Dulebohn SC, Di Napoli R. Features, evaluation and treatment coronavirus (COVID-19). InStatpearls [internet] 2020 Mar 8. StatPearls Publishing.

7. Casadevall A, Pirofski LA, Anne Pirofski L. The convalescent sera option for containing COVID19. J Clin Invest. 2020; 130:1545-8.

8. Ofori-Attah S. Dentistry and why it is a great career. Br Dent J. 2017; 223:81-4.

9. Nejatidanesh F, Khosravi Z, Goroohi H, Badrian H, Savabi O. Risk of contamination of different areas of dentist's face during dental practices. International journal of preventive medicine. 2013 May;4(5):611-615.

10. The New York Times. The workers who face the greatest coronavirus risk.

11. Ge ZY, Yang LM, Xia JJ, Fu XH, Zhang YZ. Possible aerosol transmission of COVID-19 and special precautions in dentistry. Journal of Zhejiang University-SCIENCE B. 2020 Mar 16:18.

12. Tam, CWC, Pang EPF, Lam LCW, Chiu HFK. Severe acute respiratory syndrome (SARS) in Hongkong in 2003: Stress and psychological impact among frontline healthcare workers. Psychol Med. 2004, 34, 1197-1204.

13. McAlonan GM, Lee AM, Cheung V, Cheung C, Tsang KW, Sham PC, Chua SE, Wong JG. Immediate and sustained psychological impact of an emerging infectious disease outbreak on health care workers. The Canadian Journal of Psychiatry. 2007 Apr;52(4):241-7.

14. Guan WJ, Ni ZY, Hu Y, Liang WH, Ou CQ, He JX, Liu L, Shan H, Lei CL, Hui DS, Du B. Clinical characteristics of coronavirus disease 2019 in China. New England journal of medicine. 2020 Apr 30;382(18):1708-20.

15. Harrel SK, Molinari J. Aerosols and splatter in dentistry: a brief review of the literature and 
infection control implications. J Am Dent Assoc, 2004; 135(4):429-437.

16. Cochran MA, Miller $\mathrm{CH}$, Sheldrake MA. The efficacy of the rubber dam as a barrier to the spread of microorganisms during dental treatment. J Am Dent Assoc, 1989; 119(1):141-144.

17. Samaranayake LP, Peiris M. Severe acute respiratory syndrome and dentistry: a retrospective view. J Am Dental Assoc, 2004; 135(9):12921302.

18. Feres M, Figueiredo LC, Faveri M, Stewart B, de Vizio W. The effectiveness of a preprocedural mouthrinse containing cetylpyridinium chloride in reducing bacteria in the dental office. The Journal of the American Dental Association. 2010 Apr $1 ; 141(4): 415-22$.

19. Marui VC, Souto ML, Rovai ES, Romito GA, Chambrone L, Pannuti CM. Efficacy of preprocedural mouthrinses in the reduction of microorganisms in aerosol: a systematic review. The Journal of the American Dental Association. 2019 Dec 1;150(12):1015-26.
20. Wood A, Payne D. The action of three antiseptics/ disinfectants against enveloped and non enveloped viruses. J Hosp Infect, 1998; 38(1):283-295

21. Rabenau HF, Kampf G, Cinatl J, Doerr HW. Efficacy of various disinfectants against SARS coronavirus. Journal of Hospital Infection. 2005 Oct 1;61(2):107-11.

22. Fung ICH, Cairncross S. Effectiveness of handwashing in preventing SARS: a review. Trop Med Int Health, 2006; 11(11):1749-1758.

23. WHO. Infection Prevention and Control During Health Care when Novel Coronavirus (nCoV) Infection is Suspected: Interim Guidance. World Health Organization, Geneva, Switzerland. 2020. infection-prevention-and-control-during-healthcarewhen-novel-coronavirus-(ncov)-infection-issuspected-2 0200125

24. WHO. WHO Guidelines on Hand Hygiene in Health Care: First Global Patient Safety Challenge - Clean Care is Safer Care. World Health Organization, Geneva, Switzerland. 2009. 